Please do not remove this page

RMIT

UNIVERSITY

\title{
Predicting the absorption of perforated panels backed by resistive textiles
}

Larner, David; Davy, John

https://researchrepository.rmit.edu.au/esploro/outputs/9921860672101341/filesAndLinks?institution=61RMIT_INST\&index=null

Larner, D., \& Davy, J. (2016). Predicting the absorption of perforated panels backed by resistive textiles. Noise Control Engineering Journal, 64(2), 259-267. https://doi.org/10.3397/1/376376

Document Version: Accepted Manuscript

Published Version: https://doi.org/10.3397/1/376376

Repository homepage: https://researchrepository.rmit.edu.au

(C) INCE-USA

Downloaded On 2023/04/26 21:57:15 +1000

Please do not remove this page 
Thank you for downloading this document from the RMIT Research Repository.

The RMIT Research Repository is an open access database showcasing the research outputs of RMIT University researchers.

RMIT Research Repository: http://researchbank.rmit.edu.au/

\author{
Citation: \\ Larner, D and Davy, J 2016, 'Predicting the absorption of perforated panels backed \\ by resistive textiles', Noise Control Engineering Journal, vol. 64, no. 2, pp. 259-267.
}

See this record in the RMIT Research Repository at:

https://researchbank.rmit.edu.au/view/rmit:36246

Version: Accepted Manuscript

Copyright Statement:

(c) INCE-USA

Link to Published Version:

https://dx.doi.org/10.3397/1/376376 


\section{Predicting the absorption of perforated panels backed by resistive}

\section{textiles}

David James Larner ${ }^{\mathrm{a}), \mathrm{b})}$, John Laurence Davy ${ }^{\mathrm{a}), \mathrm{c})}$

This paper studies the diffuse field sound absorption coefficient of a system consisting of a rigid perforated panel with a thin porous woven/matted material glued to its back, which is placed in front of an air cavity with a rigid backing. To cut the cost of trial and error diffuse field sound absorption coefficient measurements, a prediction method was developed. Measurements were made in a two-microphone impedance tube of the complex specific acoustic impedances of the un-perforated rigid panel materials, and of the thin porous materials in front of a rigidly terminated air cavity. These values were used in the transfer matrix method to predict the complex specific acoustic impedances of the perforated panels systems as a function of the angle of incidence of the sound. These calculations assumed the systems to have infinite or finite lateral extent. The measured diffuse field sound absorption coefficient values usually lay between the infinite and finite predictions. The most important variables are the perforation factor of the panel, the acoustic resistance of the thin porous material and the cavity depth.

Primary subject classification: 35.6; Secondary subject classification: 35.2 .3

a) RMIT University, GPO Box 2476, Melbourne, VIC 3001 Australia

b) david.larner@rmit.edu.au

c) john.davy@rmit.edu.au 


\section{INTRODUCTION}

Trial and error can be an expensive task when developing new materials for perforated panel systems. To reduce the cost of diffuse field sound absorption measurements, prediction methods have been used for modeling these perforated panel systems. Bolt ${ }^{1}$ first approximated the specific acoustic impedance of a perforated metal panel by calculating the specific acoustic reactance of the air in a cylindrical hole, and adding the viscous resistance acting on the plug of air. The specific resistance and reactance of a 1 inch thick bulk porous absorber was added to that of the plug of air. This theory was revised for the case when the perforated panel was backed by a thin resistive textile instead of a bulk porous absorber ${ }^{2}$. However, for thicker panels, the theoretical and measured diffuse field sound absorption coefficient results would differ at high frequencies ${ }^{2-3}$. This is due to the fact that a locally reacting system with the ideal total resistance of close to 1.6 times the characteristic impedance of air $\left(\rho_{0} c\right)$ for optimal diffuse field sound absorption ${ }^{4}$ should have high sound absorption properties under the presumption of this method (Equivalent circuit method - ECM), but in reality, there is a drop in performance in the high frequencies ${ }^{5}$. To rectify this, the transfer matrix method is implemented to take into account the change of specific acoustic impedances of layers ${ }^{6}$, dependent on the previous layer's specific acoustic impedance.

The complex specific acoustic impedance of the apertures of the perforated panel was calculated by using predictions of the complex characteristic acoustic impedance and complex wavenumber of the apertures of the perforated $\operatorname{panel}^{7}$, and using the transfer matrix method ${ }^{8-9}$ to implement the acoustic impedance at the front of the system. The complex specific acoustic impedance of the thin porous material is added to the complex specific acoustic impedance of the air cavity, where the perforation ratio of the panel divides the impedance of the thin porous material. Unlike micro-perforated panels (MPPs) $)^{10-12}$, perforated panels need resistance added to the system to improve the 
diffuse field sound absorption coefficient across multiple frequencies, due to the large size of the perforations in the panel. These panels also differ from MPPs due to the higher perforation ratios of the panel, which if able to be structurally integral, can have perforation ratio of up to 0.5 . However, from an industry standpoint, architects prefer lower perforations. Thus a range of panels with perforation ratios from 0.100 to 0.263 have been used in this paper.

The complex specific impedance of the panel material is placed in parallel with the complex specific impedance of the system, as this material can be absorptive. The infinite radiation impedance was originally used to predict the diffuse field sound absorption. However, this usually under-predicts compared to the measured values. Therefore, the finite radiation impedance was used in the calculation of the diffuse field sound absorption ${ }^{13-14}$. This method over-predicts the measured values, which means that the average between the infinite and finite analysis can be used as an estimate of the diffuse field sound absorption coefficient.

It must be stated that these measured reverberation room results were obtained from various industry reports where developing suitable thin resistive textiles was the basis of investigation. A typical reverberation room measurement of these MDF perforated panels and a resistive textile used is shown in Fig. 1.

\section{THEORY}

\subsection{Prediction of the diffuse field sound absorption coefficient of an infinite perforated panel}

In theory, the specific acoustic impedance of the rigidly terminated air cavity $Z_{\text {cav }}$, at the back of the holes in the perforated panel is considered to be the first layer using the transfer matrix method, and thus needs to be calculated first, 


$$
Z_{\text {cav }}=-j p \rho_{0} c \cot (k D \cos \theta) / \cos \theta
$$

where $p$ is the open-area perforation ratio of the panel, $k$ is the wavenumber of air, $D$ is the air cavity depth, and $\theta$ is the angle of incidence. The reason for the multiplication of the perforation ratio here is the difference between the acoustic particle velocity inside and outside the holes.

End corrections of the perforated panel $Z_{E C}$ need to be taken into account, as added resistance due to the viscous boundary of air at the surface of the panel and the reactance due to the radiation impedance of the holes are factors in the total impedance of the system ${ }^{15}$. The resistive end correction for one side of the panel can be calculated as;

$$
\operatorname{Re}\left(Z_{E C}\right)=\frac{1}{8} \sqrt{2 \mu \rho_{0} c k}
$$

where $\mu$ is the dynamic viscosity of air $\left(1.84 \times 10^{-5}\right)$. Depending on if the perforation is shaped as a circle ${ }^{15}$ or slit ${ }^{16}$, the reactance end correction can be calculated as;

$$
\begin{gathered}
\operatorname{Im}\left(Z_{E C, \text { cir }}\right)=-\rho_{0} c \frac{4 k d}{3 \pi} \\
\operatorname{Im}\left(Z_{E C, \text { slit }}\right)=-\frac{\rho_{0} c k a}{\pi} \ln \left[\sin \left(\frac{\pi p}{2}\right)\right]
\end{gathered}
$$

where $d$ is the diameter of the circular perforation, and $a$ is the width of the slit perforation.

Here, the measured complex specific acoustic impedance of the thin porous material $Z_{\text {woven }}$ is added to the impedance of the air cavity ${ }^{17}$ and the end corrections, as the combination of all three can be considered to be a single layer with a specific acoustic impedance of $Z_{1}$. 


$$
Z_{1}=Z_{\text {woven }}+Z_{\text {cav }}+Z_{E C}
$$

End corrections for a resistive textile can be calculated theoretically ${ }^{18}$ to take into account the interaction between the pores in a textile (which can be calculated for a woven material) and the dynamic tortuosity of the textile. Since the impedance of the textile is measured, these end corrections are included in the measured data.

To calculate the specific acoustic impedance of the perforated panel using the transfer matrix method, the complex characteristic impedance and complex wavenumber of the perforated panel needs to be calculated ${ }^{7}$. These values are calculated using the effective density $\rho_{e}$ and the effective bulk modulus $K$. For circular apertures, the bulk modulus (at $18^{\circ} \mathrm{C}$ ) can be calculated by;

$$
K_{c i r}=\gamma P_{o} /\left[1+(\gamma-1) \frac{2}{B s \sqrt{-j}} \frac{J_{1}(B s \sqrt{-j})}{J_{0}(B s \sqrt{-j})}\right]
$$

where $\gamma$ is the adiabatic constant of air, $P_{o}$ is the ambient mean pressure, $B$ is the square root of the Prandtl number $(\sqrt{ } 0.71)$, and $J_{n}$ is the $n^{\text {th }}$ order Bessel function of the first kind. $s$ is equal to;

$$
s=\sqrt{\frac{\omega \rho_{0} R^{2}}{\eta}}
$$

where $\omega$ is the angular frequency, $\rho_{0}$ is the density of air, $R$ is the radius of the aperture, and $\eta$ is the viscosity of air.

These previous two equations can be modified for slits ${ }^{7}$;

$$
K_{\text {slit }}=\gamma P_{o} /\left[1+(\gamma-1) \frac{\tanh \left(B s^{\prime} \sqrt{j}\right)}{B s^{\prime} \sqrt{j}}\right]
$$




$$
s^{\prime}=\sqrt{\frac{\omega \rho_{0} a^{2}}{\eta}}
$$

The effective density is then calculated, for both circular apertures $\rho_{e_{c i r}}$ and slits $\rho_{e_{\text {slit }}}$ respectively $^{7}$

$$
\begin{gathered}
\rho_{e_{\text {cir }}}=\rho_{0} /\left[1-\frac{2}{s \sqrt{-j}} \frac{J_{1}(s \sqrt{-j})}{J_{0}(s \sqrt{-j})}\right] \\
\rho_{e_{s l i t}}=\rho_{0} /\left[1-\frac{\tanh \left(s^{\prime} \sqrt{j}\right)}{s^{\prime} \sqrt{j}}\right]
\end{gathered}
$$

From these calculations, the complex characteristic impedance $Z_{c}$ and complex wavenumber $k^{\prime}$ of the perforated panel can be calculated;

$$
\begin{gathered}
Z_{c}=\sqrt{K \rho_{e}} \\
k^{\prime}=\omega \sqrt{\rho_{e} / K}
\end{gathered}
$$

There needs to be an angular dependent term when calculating the specific acoustic impedance of the apertures in the perforated panel. This is obtained when calculating the component of the vector of the complex wavenumber in the direction perpendicular to the face of the panel $k^{\prime}{ }_{3}$

$$
k_{3}^{\prime}=\sqrt{k^{\prime 2}-k_{0}^{2} \sin ^{2}(\theta)}
$$

With these values, the specific acoustic impedance of the apertures in the panel $Z_{0}$ can now be calculated ${ }^{8}$

$$
Z_{0}=\frac{Z_{c}}{p} \frac{k^{\prime}}{k^{\prime}{ }_{3}} \frac{-j Z_{1} \cot \left(k^{\prime}{ }_{3} t\right)+Z_{c} k^{\prime} / k^{\prime}{ }_{3}}{Z_{1}-j Z_{c} k^{\prime} \cot \left(k^{\prime}{ }_{3} t\right) / k^{\prime}{ }_{3}}+\frac{Z_{E C}}{p}
$$

where $t$ is the thickness of the panel. The end corrections of the perforations are added 
here for the surface side of the panel. To obtain the total impedance of the system, the material impedance of the panel needs to be incorporated into the system, as materials such as MDF (medium density fibreboard) have absorptive properties in the high frequency range. The panel material impedance of an unperforated sample $Z_{\text {panel }}$ is used in parallel with the aperture impedances, to give the total impedance of the system;

$$
Z_{\text {tot }}=\left(\frac{1}{Z_{0}}+\frac{1-p}{Z_{\text {panel }}}\right)^{-1}
$$

The diffuse field sound absorption coefficient can then be calculated for the entire system using the commonly found equation

$$
\alpha=8 \int_{0}^{\frac{\pi}{2}} \sin \theta \cos \theta \frac{\operatorname{Re}\left(Z_{t o t} / \rho_{0} c\right) \cos \theta}{\left[1+\operatorname{Re}\left(Z_{t o t} / \rho_{0} c\right) \cos \theta\right]^{2}+\left[\operatorname{Im}\left(Z_{t o t} / \rho_{0} c\right) \cos \theta\right]^{2}} d \theta
$$

\subsection{Calculation of the diffuse field absorption coefficient for a finite size panel}

The radiation impedance of a finite size panel was also used to calculate the diffuse field sound absorption coefficient, as this method tends to boost the diffuse field sound absorption coefficient values across all frequencies. This was performed by calculating the normalized complex finite radiation impedance ${ }^{13-14}$. Firstly, the real part of the normalized finite radiation impedance must be calculated:

$$
\operatorname{Re}\left(z_{F}\right)=\left[\operatorname{Re}\left(z_{F_{H}}\right)^{-2}+\left(\frac{k_{0}^{2} A}{2 \pi}\right)^{-2}\right]^{-\frac{1}{2}}
$$

where $A$ is the area of the perforated panel, and the high frequency approximation of the normalized finite impedance $z_{F_{H}}$ is

$$
z_{F_{H}}=\sqrt{\left(\cos ^{2} \theta+\left[\frac{\beta(L+W)}{A k_{0}}\right]^{2}-2 j \frac{\beta(L+W)}{A k_{0}} \sin \theta\right)^{-1}}
$$


where $L$ and $W$ are the length and width of the perforated panel respectively, and $\beta=0.956$.

The imaginary part of the normalized radiation impedance is calculated by

$$
\operatorname{Im}\left(z_{F}\right)=\left\{\begin{array}{ccc}
z_{F_{0}} & \text { if } z_{F_{0}}>\operatorname{Im}\left(z_{F_{H}}\right) \\
\operatorname{Im}\left(z_{F_{H}}\right) & \text { if } & z_{F_{0}}<\operatorname{Im}\left(z_{F_{H}}\right)
\end{array}\right.
$$

where

$$
z_{F_{0}}=\left[\left(\frac{k_{0}[W H(L / W)+L H(W / L)]}{\pi}\right)^{-2}+\left(\frac{0.67(L+W)}{k_{0} A}\right)^{-2}\right]^{-\frac{1}{2}}
$$

and

$$
H(x)=\ln \left(\sqrt{1+x^{2}}+x\right)-\frac{\sqrt{1+(x)^{2}}-1}{3 x}
$$

The complex specific acoustic impedance of the system is then calculated in the same way as the in infinite case. However, the calculation of the diffuse field absorption coefficient is slightly different:

$$
\alpha=8 \int_{0}^{\frac{\pi}{2}} \cos \theta \sin \theta \frac{\operatorname{Re}\left(Z_{t o t} / \rho_{0} c\right)}{\left|Z_{\text {tot }} / \rho_{0} c+z_{F}\right|^{2}} \frac{1}{\cos \theta} d \theta
$$

Here, the two $\cos \theta$ values will cancel each other out, resulting in the following equation

$$
\alpha=8 \int_{0}^{\frac{\pi}{2}} \sin \theta \frac{\operatorname{Re}\left(Z_{t o t} / \rho_{0} c\right)}{\left|Z_{t o t} / \rho_{0} c+z_{F}\right|^{2}} d \theta
$$

The equation can now be solved without problems due to the case when $\theta=\pi / 2$. 


\section{RESULTS}

Three thin porous materials were selected to be measured in the two-microphone impedance tube. Their impedances were used in the prediction model and compared to that of the measured reverberation room data. The flow resistance and production method of the three materials are shown in Table 1 . This measurement is performed in both a low frequency and a high frequency two-microphone impedance tube ${ }^{19}(100 \mathrm{~mm}$ and $29 \mathrm{~mm}$ diameters respectively), so a wide range of frequencies are measured (172 $5936 \mathrm{~Hz}$ ). This was performed by gluing the material to a metal mount, so the thin porous material is free standing, slightly less than one-quarter of the wavelength of the maximum frequency away from the rigid backing (this is to prevent any air cavity resonance appearing in the measurement ${ }^{20}$ ). The complex specific acoustic impedance of the air cavity used in the measurement is then subtracted from the measurements, so only the complex specific acoustic impedance of the material is added to the theoretical impedance of the air cavity behind the system whose sound absorption is being calculated.

For the panel material impedance, an unperforated MDF block was measured in the two-microphone impedance tube, when rigidly-backed, and in front of two air cavity depths. As seen in Fig. 2, the specific acoustic impedance of the $12 \mathrm{~mm}$ thick MDF block in front of two air cavities, has very similar values, which are different to those of the rigidly-backed sample, which has generally lesser magnitude values of specific acoustic impedance throughout most of the frequency range. Both the rigidly backed and $42.8 \mathrm{~mm}$ air cavity case impedance values of MDF were used in predictions during investigation, and it was found that the case where MDF was backed by an air cavity improved the agreement between the theoretical and measured diffuse field sound 
absorption coefficients for multiple systems, compared to that of the rigidly-backed MDF case. As these panel configurations were measured in a reverberation room where the panels were mounted in front of an air cavity, using the MDF impedance in front of an air cavity is appropriate for predicting the measured reverberation room data (where flexing of the MDF panel can occur).

As shown in Fig. 3, the diffuse field sound absorption coefficient of a $12 \mathrm{~mm}$ thick MDF perforated panel, with $4.5 \mathrm{~mm}$ diameter holes and a 0.102 perforation ratio, backed by Material 1 and a $90 \mathrm{~mm}$ air cavity has been calculated, averaged into third octave bands, and compared to that of measured reverberation room data (measured in accordance to ISO $354^{21}$ ). The MDF impedance is seen to be important factor in the sound absorption coefficient, especially above $1 \mathrm{kHz}$. Problems arose in the mounting of the thin porous material in the low frequency two-microphone impedance tube, as the sample (100 $\mathrm{mm}$ in diameter) is more difficult to mount in a fully taut state. When plotted in $4 \mathrm{~Hz}$ increments, this particular thin woven material had ripples in the measured values below $500 \mathrm{~Hz}$. While this is not ideal, it still provides a reasonable quantitative result. Because the low frequency impedance tube results stop at $1552 \mathrm{~Hz}$, due to limitations of the diameter of the tube, and the high frequency impedance tube results start at $864 \mathrm{~Hz}$, there is an overlap of results. These overlapped results are averaged, and fitted into their respective third octave bands.

Less flow resistive materials systems, such as the $12 \mathrm{~mm}$ thick MDF perforated panel, with $12.7 \mathrm{~mm}$ wide slots and a 0.263 perforation ratio, backed by Material 2 and a $90 \mathrm{~mm}$ air cavity were also measured to obtain a range of results, where the reverberation room data was already available, as shown in Fig. 4. With higher 
performing systems, the infinite prediction model cannot reach the peak absorption coefficient of the measured data; hence the finite method was also used. However, both models have a slight over-prediction in the $2000 \mathrm{~Hz}$ third octave band, but overall the trend of the perforated panel system has been predicted relatively well.

Since most perforated panel systems can range in cavity depth, other air cavities had to be explored. In Fig. 5, a $12 \mathrm{~mm}$ thick MDF perforated panel, with $10 \mathrm{~mm}$ diameter holes and a 0.251 perforation ratio, backed by Material 1 and a $400 \mathrm{~mm}$ air cavity was predicted. In this particular case, the finite model using Eqn. (24) has the most similar absorption values to that of the measured data across most of the frequency range, even though the infinite model has a very similar shape to the measured data. This shows that these prediction models are suitable for larger air cavity systems, as well as larger perforation ratio panels.

A third material (Material 3) was investigated, where the specifications of the test were all stated except for the thickness of the panel. While comparison to the measured data cannot be used with prediction without knowing the thickness of the panel, observations of the nature of the absorption coefficient can still be made. Instead of plotting the data in third octaves, both the low and high frequency impedance tube values of measured specific acoustic impedance of the textile is used for clarity. While there is a discontinuity between the low and high frequency samples due to difference in size and mounting conditions, the overall trend can be observed in Fig. 6. Because this particular panel was made of steel, the impedance of the panel material was considered to be infinite, and thus only the prediction of the specific acoustic impedance of the perforated panel calculated in Eqn. (15) was used. The major observation noticed in Fig. 
6 was that for a panel with $1.8 \mathrm{~mm}$ diameter holes, a perforation ratio of 0.100 backed by a $400 \mathrm{~mm}$ air cavity, for extremity sake, Material 3 (left) performed better overall behind a $1 \mathrm{~mm}$ thick panel rather than a $20 \mathrm{~mm}$ thick panel. While the thinner the panel, the better the performance is widely-known, investigation into why this is the case has not been concluded. For comparisons sake, Material 1 (Fig. 6 - right) was also placed behind these two panel thicknesses as well, and the more resistive textile had a trend where, in the very high frequencies $(5 \mathrm{kHz}+)$, the thicker panel was outperforming the thinner panel. Comparisons of both Materials' $20 \mathrm{~mm}$ thick panel will also show that the higher resistive material (Material 1) will outperform the less resistive material (Material 3) in the high frequencies $(3.15 \mathrm{kHz}+)$. This trend is not observed using the electrical circuit method, as that model suggests that the less resistive material, (which, after an appropriate perforation ratio is applied, is closer to the ideal total impedance of $\sim 2 \rho_{0} c$ ) will always outperform the higher resistive material across all frequencies, regardless of panel thickness. Using Eqn. (15), assuming normal incidence, normalizing the values by dividing the characteristic impedance of air, and rearranging, the calculation of the normalized specific acoustic impedance of the perforated panel $z_{0}$ becomes;

$$
z_{0}=\frac{1}{p} \frac{z_{1}+j T}{1+j z_{1} T}+\frac{z_{E C}}{p}
$$

where $T=\tan \left(k^{\prime} t\right)$, and $z_{1}$ is the normalized specific acoustic impedance of the addition of the air cavity and the resistive material behind the perforated panel. If $z_{1}$ is then broken up into real and imaginary parts ( $r$ and $x$ respectively), $z_{0}$ becomes;

$$
z_{0}=\frac{1}{p} \frac{r+j(x+T)}{1-x T+j r T}+\frac{z_{E C}}{p}
$$




$$
\begin{gathered}
z_{0}=\frac{1}{p} \frac{[r+j(x+T)][(1-x T)-j r T]}{(1-x T)^{2}+(r T)^{2}}+\frac{z_{E C}}{p} \\
z_{0}=\frac{1}{p} \frac{r(1-x T)+r T(x+T)+j\left[(x+T)(1-x T)-r^{2} T\right]}{(1-x T)^{2}+(r T)^{2}}+\frac{z_{E C}}{p} \\
z_{0}=\frac{1}{p} \frac{r\left(1+(T)^{2}\right)+j\left[x-x^{2} T+T-x(T)^{2}-r^{2} T\right]}{1-2 x T+T^{2}\left(r^{2}+x^{2}\right)}+\frac{z_{E C}}{p}
\end{gathered}
$$

The real part of this equation becomes;

$$
\operatorname{Re}\left(z_{0}\right)=\frac{1}{p} \frac{r\left(1+\left(\tan \left(k^{\prime} t\right)\right)^{2}\right)}{1-2 x \tan \left(k^{\prime} t\right)+\left(\tan \left(k^{\prime} t\right)\right)^{2}\left(r^{2}+x^{2}\right)}+\frac{\operatorname{Re}\left(z_{E C}\right)}{p}
$$

In other words, the resistance of the panel is dependent on the specific acoustic impedance of the air cavity, material resistance and mass, end corrections, and thickness of the panel. Ideally, the mass of the holes in the resistive textile would cancel out with the stiffness of the air cavity, but as this is extremely difficult to implement in real circumstances, the values of $x$ were calculated using the imaginary parts of Eqn. (5), where the mass of the textile is $0 . r$ is considered to be the resistance of the textile and the resistive end correction of one side of the panel.

In Fig. 7, the ideal value of the normalized resistance of the diffuse field system should be close to 2 , which lies between the normalized material resistance values of 0.15 and 0.25 for most of the frequency range. However, it can be seen from $2 \mathrm{kHz}$ onwards, that the normalized values of resistance start to interchange with each other, and the least resistant materials dramatically increase the resistance at the high frequencies. This explains the high frequency behavior seen in Fig. 5. To show why the performance of Material 3 did not decrease with a $1 \mathrm{~mm}$ thick panel, the normalized resistance of the system with a $1 \mathrm{~mm}$ thick panel is plotted in Fig. 8. For a $1 \mathrm{~mm}$ thick perforated panel, the resistance stays roughly the same resistance throughout the frequency range, with exception of the resonances of the air cavity. This shows that if 
perforated panel systems are to be designed to be high performance absorbers over the frequency range of $100 \mathrm{~Hz}-6000 \mathrm{~Hz}$, it can be a trade-off between high performance in the low to mid frequency range, and high performance in the high frequency range. However, frequencies above $3000 \mathrm{~Hz}$ do not affect single number absorption ratings such as NRC.

Since the NRC (Noise Reduction Coefficient) ${ }^{22}$ is one of the common forms of rating a diffuse field sound absorption system, the measured and predicted NRC values were compared to give a rough idea on how well the predicted values agree with the measured values. The NRC rating involves averaging the diffuse field absorption values from the $250 \mathrm{~Hz}, 500 \mathrm{~Hz}, 1 \mathrm{kHz}$ and $2 \mathrm{kHz}$ third octave bands. Due to the overlap of frequencies between $864 \mathrm{~Hz}-1552 \mathrm{~Hz}$, the predicted diffuse field sound absorption coefficient values were averaged before being used in the calculation of the NRC.

As shown in Table 2, the predicted NRC values are the same or one 0.05 increment higher or lower than the measured NRC values.

\section{CONCLUSION}

With a range of panel thickness, panel perforation ratio, panel perforation size, thin porous materials and air cavity depths, a prediction model for the diffuse field sound absorption coefficient measured in a reverberation room was implemented, with NRC readings equal to, or one $\mathrm{NRC}$ increment of 0.05 either side of the measured NRC values. This model can be used to quantitatively predict the diffuse field sound absorption coefficient. This eliminates the trial and error methods of reverberation room testing of large sample sound absorption systems. 


\section{REFERENCES}

1. R. Bolt, "On the Design of Perforated Facings for Acoustical Materials", J. Acoust. Soc. Am., 19(5), 917-23, (1947).

2. U. Ingard and R. Bolt, "Absorption Characteristics of Acoustical Material with Perforated Facings”, J. Acoust. Soc. Am., 23 (5), 533-40, (1951).

3. J. Pfretzschner, F. Simón, and C. de la Colina, "Acoustic absorbent panels with low perforation coefficient”, Acústica 2004, (2004)

4. W. A. Davern, "Perforated facings backed with porous materials as sound absorbers-An experimental study", Appl. Acoust., 10(2), 85-112, (1977).

5. E. E. Mikeska and R.N. Lane, "Measured Absorption Characteristics of Resonant Absorbers Employing Perforated Panel Facings", J. Acoust. Soc. Am., 28(5), 987-992, (1956).

6. J. Zou, Y. Shen, J. Yang and X. Qiu, "A note on the prediction method of reverberation absorption coefficient of double layer micro-perforated membrane", Appl. Acoust., 67(2), 106-111, (2006).

7. J. Allard and N. Atalla, "Sound propagation in cylindrical tubes and porous materials having cylindrical pores", Chap. 4 of Propagation of Sound in Porous Media: Modelling Sound Absorbing Materials, $2^{\text {nd }}$ Edition, John Wiley \& Sons Ltd, The Atrium, Southern Gate, Chichester, West Sussex, (2009).

8. J. Allard and N. Atalla, "Acoustic impedance at oblique incidence in fluids. Substitution of a fluid layer for a porous layer", Chap. 3 of Propagation of Sound in Porous Media: Modelling Sound Absorbing Materials, $2^{\text {nd }}$ Edition, John Wiley \& Sons Ltd, The Atrium, Southern Gate, Chichester, West Sussex, (2009).

9. C. Zwikker and C.W. Kosten, Sound absorbing materials, Elsevier Pub. Co., New York, (1949).

10. D. Y. Maa, "Theory and design of microperforated panel sound-absorbing constructions", Sci. Sinica, 18(1), 55-71, (1975).

11. J. Kang and H. V. Fuchs, "Predicting the absorption of open weave textiles and microperforated membranes backed by an air space", J. Sound Vib., 220(5), 905-920, (1999).

12. K. Sakagami, S. Kobatake, K. Kano, M. Morimoto and M. Yairi, "Sound absorption characteristics of a single microperforated panel absorber backed by a porous absorbent layer", Acoust. Aust., 39(3), 95-100, (2011).

13. S-I. Thomasson, "Theory and experiments on the sounds absorption as function of the area", Royal Institute of Technology, Stockholm, Sweden, Report TRITA-TAK-8201, May (1982).

14. J. Davy, D. Larner, R. Wareing and J. Pearse, "The average specific forced radiation wave impedance of a finite rectangular panel", J. Acoust. Soc. Am., 136(2), 525-536, (2014)

15. U. Ingard, "On the theory and design of acoustic resonators", J. Acoust. Soc. Am., 25(6), 1037-1061, (1953).

16. F. P. Mechel, "Radiation of sound", Chap. F of Formulas of Acoustics, $2^{\text {nd }}$ Edition, SpringerVerlag, Berlin, (2008). 
17. L. Jaouen and F.-X. Bécot, "Acoustical characterization of perforated facings", J. Acoust. Soc. Am., 129(3), 1400-1406, (2011).

18. N. Atalla and F. Sgard, "Modelling of perforated plates and screens using rigid frame porous models", J. Sound Vib., 303(1-2), 195-208, (2007)

19. Acoustics - Determination of sound absorption coefficient and impedance in impedance tubes - Part 2: Transfer-function method, International Standard ISO 10534-2: 1998, International Organization for Standardization, Geneva, Switzerland (1998).

20. D. J. Larner and J. L. Davy, "The prediction of the complex characteristic acoustic impedance of porous materials", Internoise 2014, (2014)

21. Acoustics - Measurement of sound absorption in a reverberation room, International Standard ISO 354: 2003, International Organization for Standardization, Geneva, Switzerland (2003)

22. Standard test method for sound absorption and sound absorption coefficients by the reverberation room method, ASTM C423-09, American Society for Testing and Materials International, West Conshohocken, Pennysylvania, United States (2009) 
David James Larner

Table 1 - Thin porous materials used in-conjunction with perforated panels

\begin{tabular}{cccc}
\hline \hline Material \# & $\begin{array}{c}\text { Thickness } \\
(\mathrm{mm})\end{array}$ & $\begin{array}{c}\text { Flow Resistance } \\
(\mathrm{mks} \text { rayl })\end{array}$ & Production \\
\hline 1 & 0.3 & 746 & Woven \\
2 & 0.1 & 273 & Woven \\
3 & 0.2 & 243 & Matted \\
\hline \hline
\end{tabular}


Table 2 - Predicted and Measured NRC (Noise Reduction Coefficient) values

\begin{tabular}{ccccc}
\hline \hline System & $\begin{array}{c}\text { Infinite } \\
\text { NRC } \\
\text { prediction }\end{array}$ & $\begin{array}{c}\text { Finite NRC } \\
\text { prediction }\end{array}$ & $\begin{array}{c}\text { Rounded } \\
\text { average } \\
\text { predicted } \\
\text { NRC }\end{array}$ & $\begin{array}{c}\text { Measured } \\
\text { NRC }\end{array}$ \\
\hline Fig. 1 & 0.55 & 0.55 & 0.55 & 0.60 \\
Fig. 2 & 0.65 & 0.65 & 0.65 & 0.70 \\
Fig. 3 & 0.70 & 0.75 & 0.75 & 0.70 \\
Fig. 4 & 0.65 & 0.75 & 0.70 & 0.75 \\
\hline \hline
\end{tabular}




\section{LIST OF FIGURE CAPTIONS}

Fig. 1 - Reverberation room setup of a $12 \mathrm{~mm}$ thick $M D F$ slotted panel backed by a resistive textile and $400 \mathrm{~mm}$ air cavity (left), and a typical acoustic textile used in these reverberation room measurements (right).

Fig. 2 - Normalized specific acoustic impedance of a $12 \mathrm{~mm}$ thick unperforated MDF block. The left and right plots show the normalized resistance and reactance of the MDF block, when the block is backed by a rigid-backing (blue), $21.5 \mathrm{~mm}$ air cavity (green) and $42.8 \mathrm{~mm}$ air cavity (red).

Fig. 3 -Diffuse field sound absorption coefficient of a $12 \mathrm{~mm}$ thick MDF perforated panel, with $4.5 \mathrm{~mm}$ diameter holes and a 0.102 perforation ratio, backed by Material 1 and a $90 \mathrm{~mm}$ air cavity. The black line shows the measured reverberation room data, and the red and blue lines show the finite and infinite size radiation impedance predictions respectively. The magenta line shows the infinite prediction model without the MDF impedance in parallel with the specific acoustic impedance of the system. The resistive textile is considered infinitely thin in the prediction model.

Fig. 4 - Diffuse field sound absorption coefficient of a $12 \mathrm{~mm}$ thick MDF perforated panel, with $12.7 \mathrm{~mm}$ wide slots and a 0.263 perforation ratio, backed by Material 2 and a $90 \mathrm{~mm}$ air cavity. The black line shows the measured reverberation room data, and the red and blue lines show the finite and infinite size radiation impedance predictions respectively. The resistive textile is considered infinitely thin in the prediction model.

Fig. 5 - Diffuse field sound absorption coefficient of a $12 \mathrm{~mm}$ thick MDF perforated panel, with $10 \mathrm{~mm}$ diameter holes and a 0.251 perforation ratio, backed by Material 1 and a 400 mm air cavity. The black line shows the measured reverberation room data, and the $\mathrm{red} /$ magenta and blue lines show the finite and infinite size radiation impedance predictions respectively. The resistive textile is considered infinitely thin in the prediction model.

Fig. 6 -Diffuse field sound absorption coefficient of a steel perforated panel, with $1.8 \mathrm{~mm}$ diameter holes, and a 0.1 perforation ratio, backed by a resistive textile and a $400 \mathrm{~mm}$ air cavity. The left and right plots are of Material 3 and 1 respectively, and the blue and red lines shows the predicted infinite absorption coefficient of a $20 \mathrm{~mm}$ thick or $1 \mathrm{~mm}$ thick panel respectively. The resistive textile is considered infinitely thin in the prediction model. The discontinuity between the low and high frequency plots are due to the difference in mounting conditions and size of the samples in the low and high frequency impedance tubes. 
Fig. 7 - Normalized resistance $R e\left(z_{0}\right)$ of a $12 \mathrm{~mm}$ thick perforated panel with $4.5 \mathrm{~mm}$ diameter holes and a perforation ratio of 0.102, backed by a thin porous material and a 400 mm air cavity at normal incidence vs. Frequency. Resonances in the data are due to the air cavity impedance. $r$ denotes the normalized resistance of the thin porous material and panel end correction.

Fig. 8 - Normalized resistance Re $\left(z_{0}\right)$ of a $1 \mathrm{~mm}$ thick perforated panel with $4.5 \mathrm{~mm}$ diameter holes and a perforation ratio of 0.102, backed by a thin porous material and a 90 mm air cavity at normal incidence vs. Frequency. Resonances in the data are due to the air cavity impedance. $r$ denotes the normalized resistance of the thin porous material and panel end correction. 


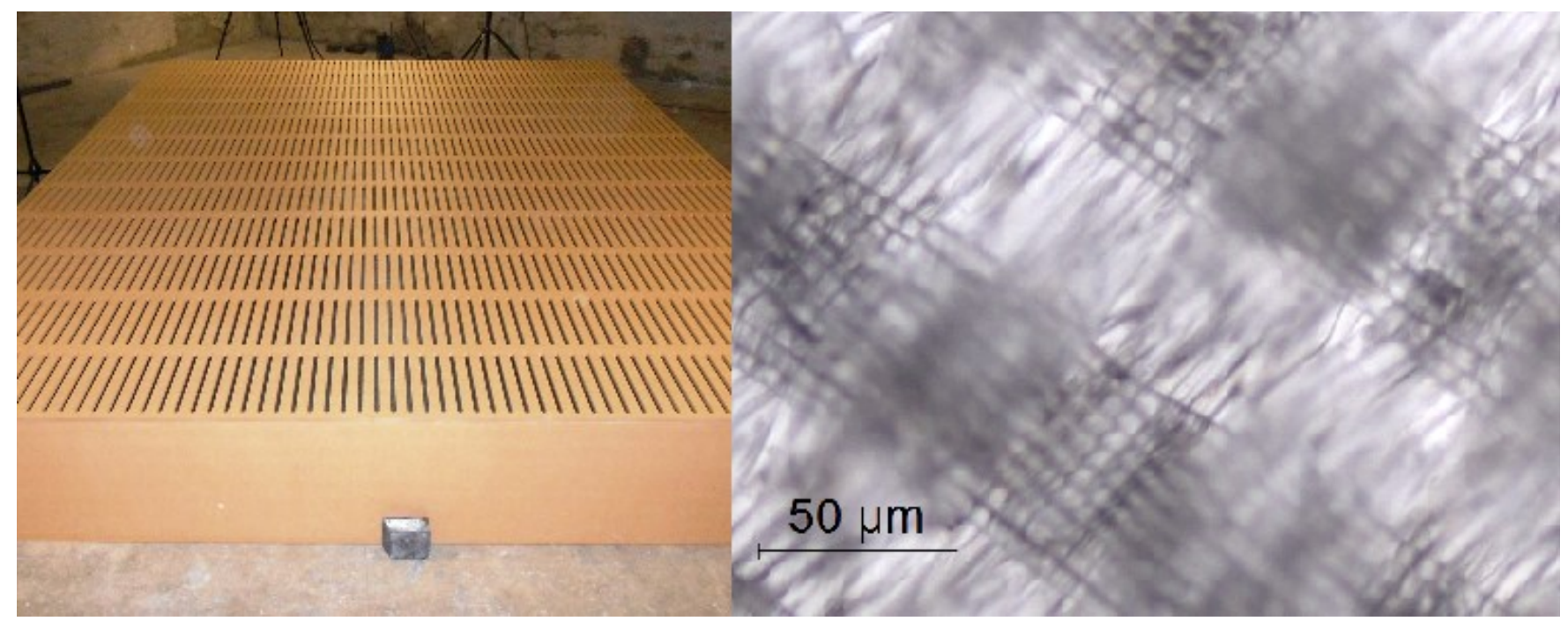

Fig. 1 

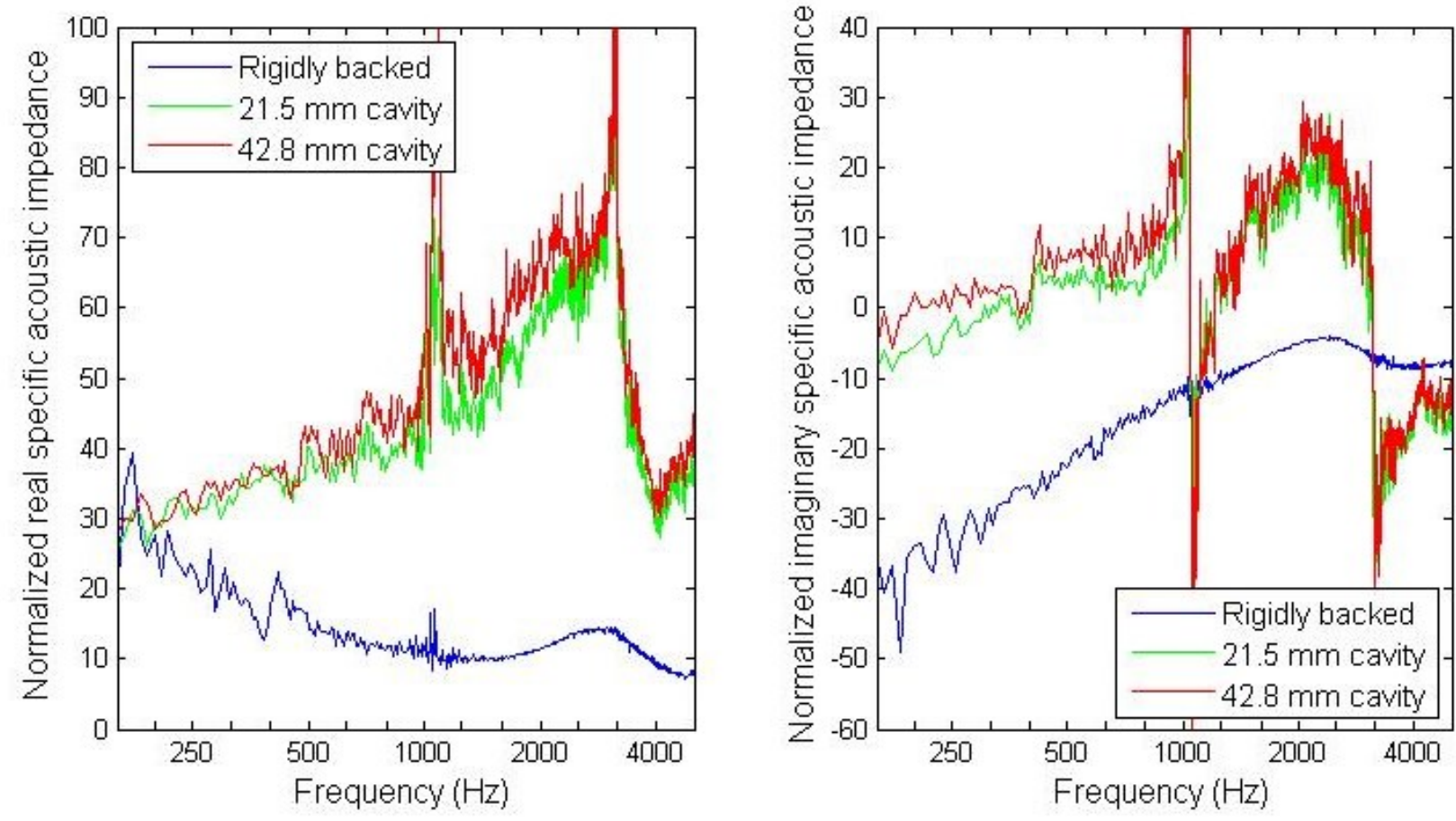

Fig. 2 


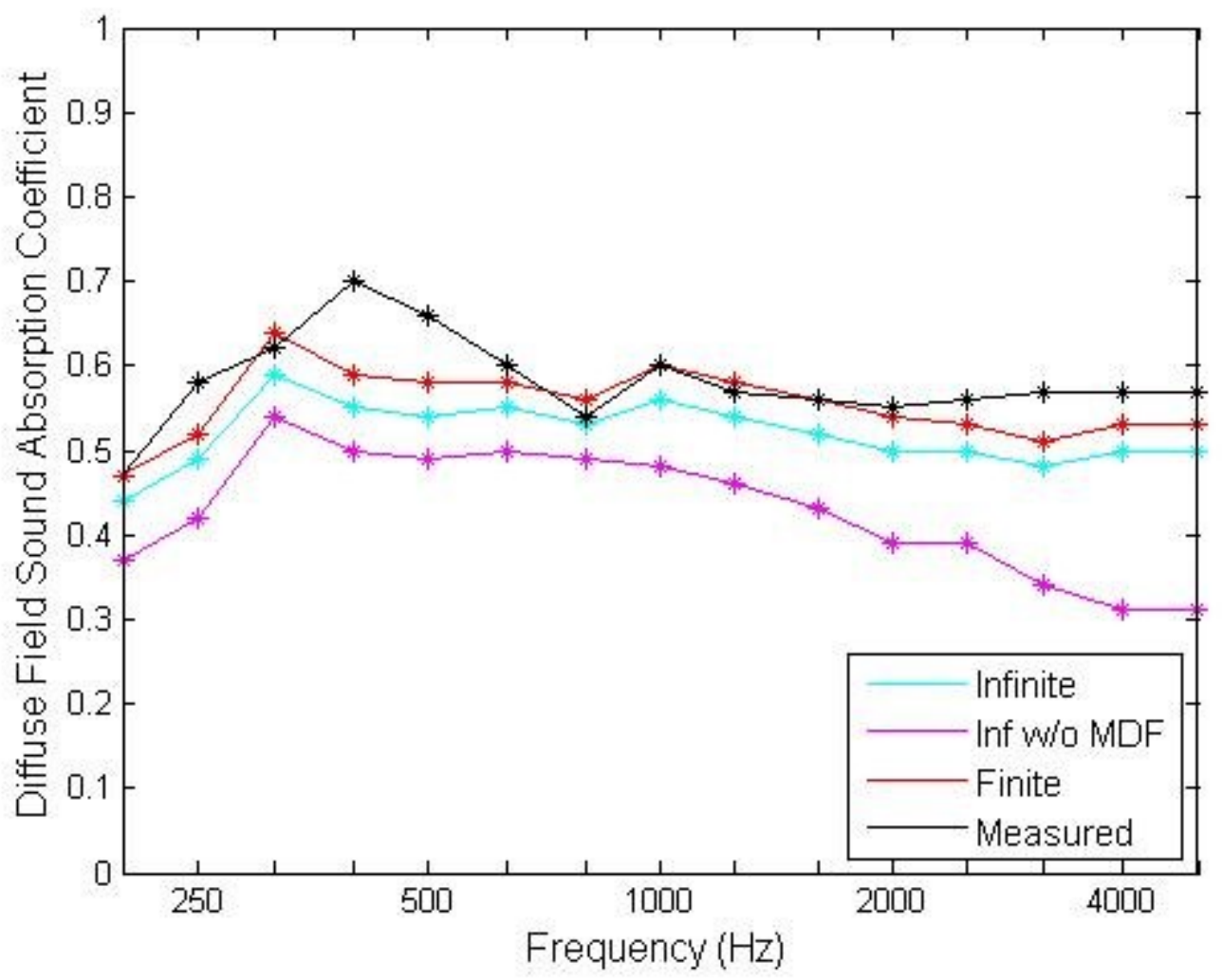

Fig. 3 


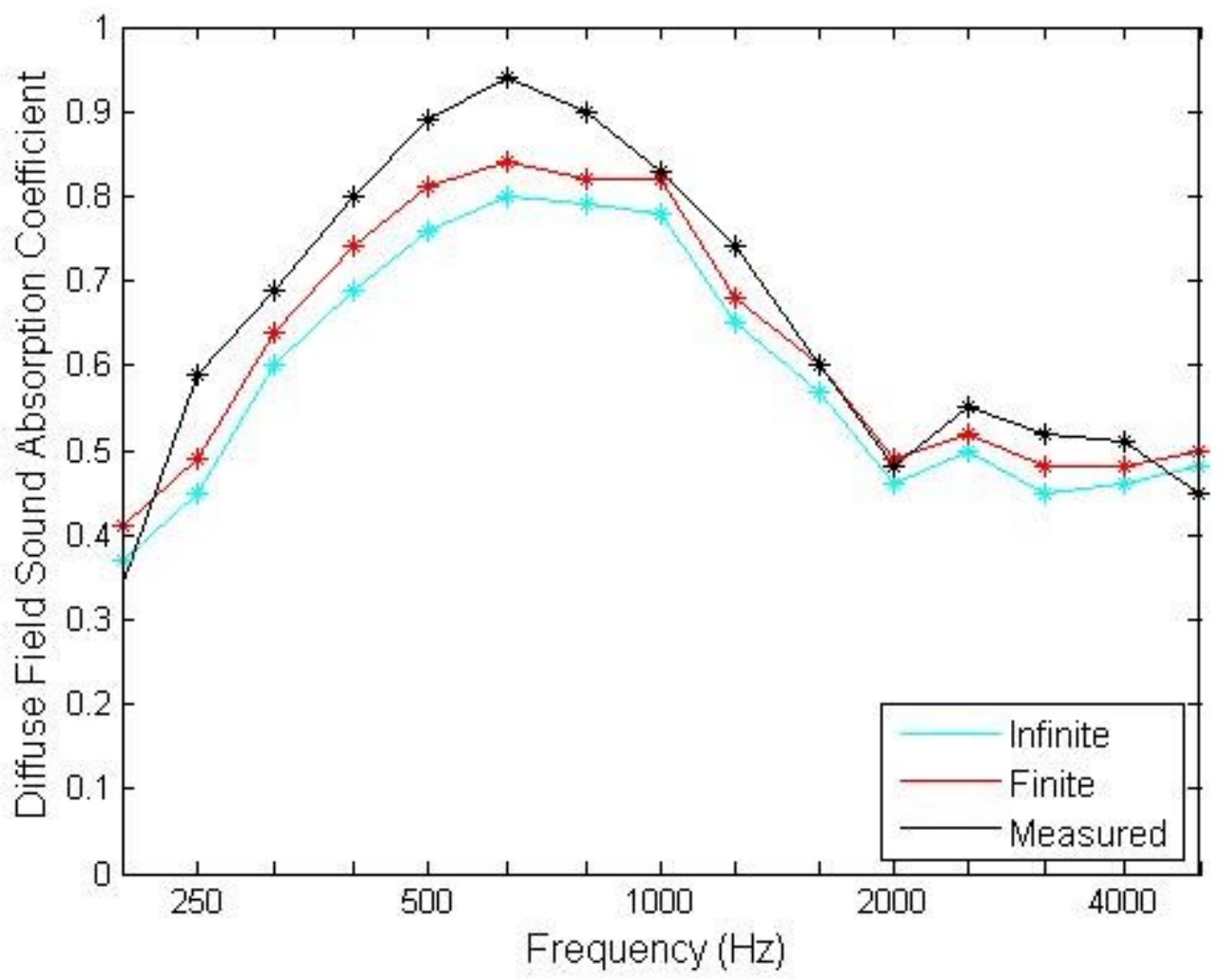

Fig. 4 


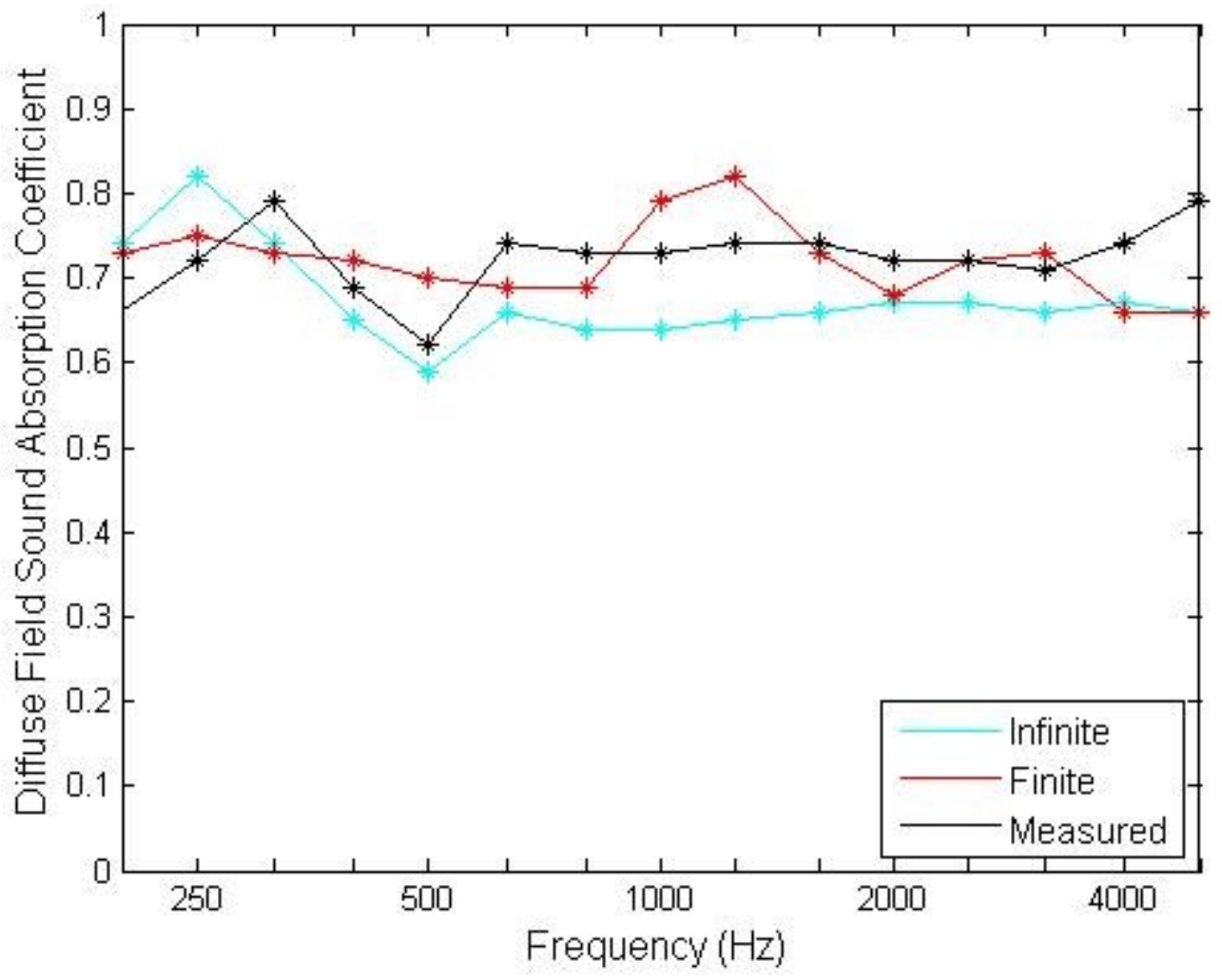

Fig. 5 

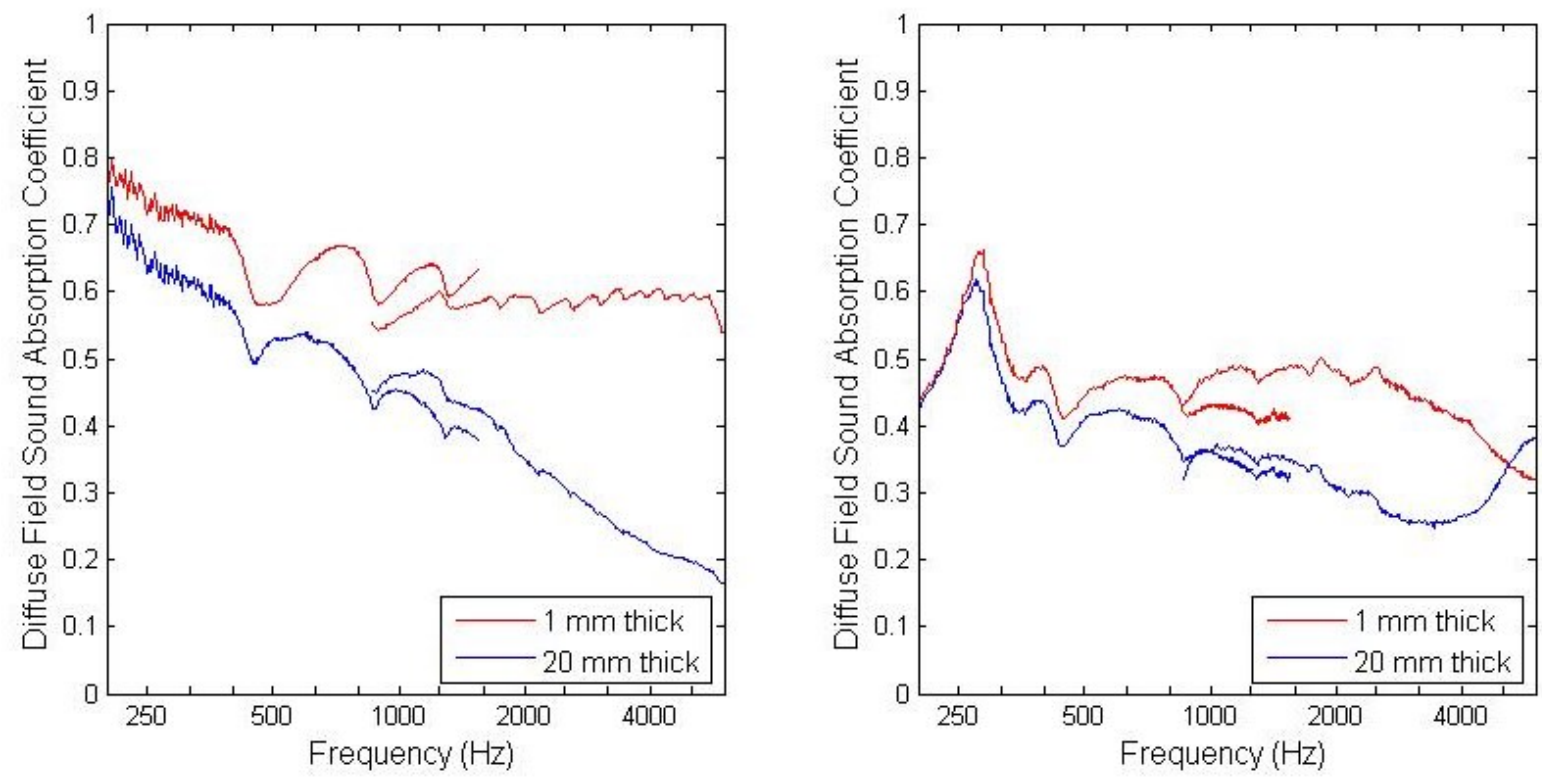

Fig. 6 


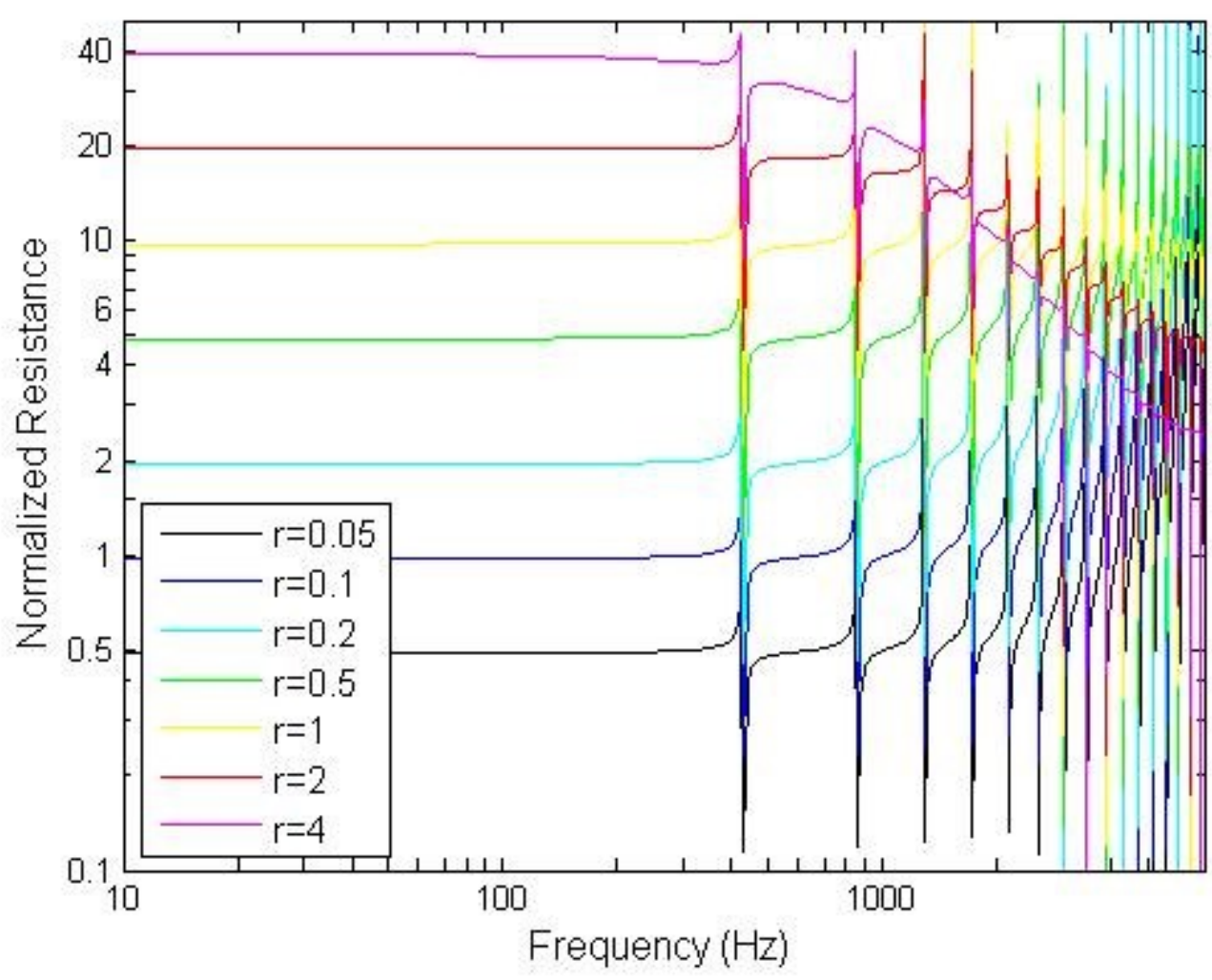

Fig. 7 


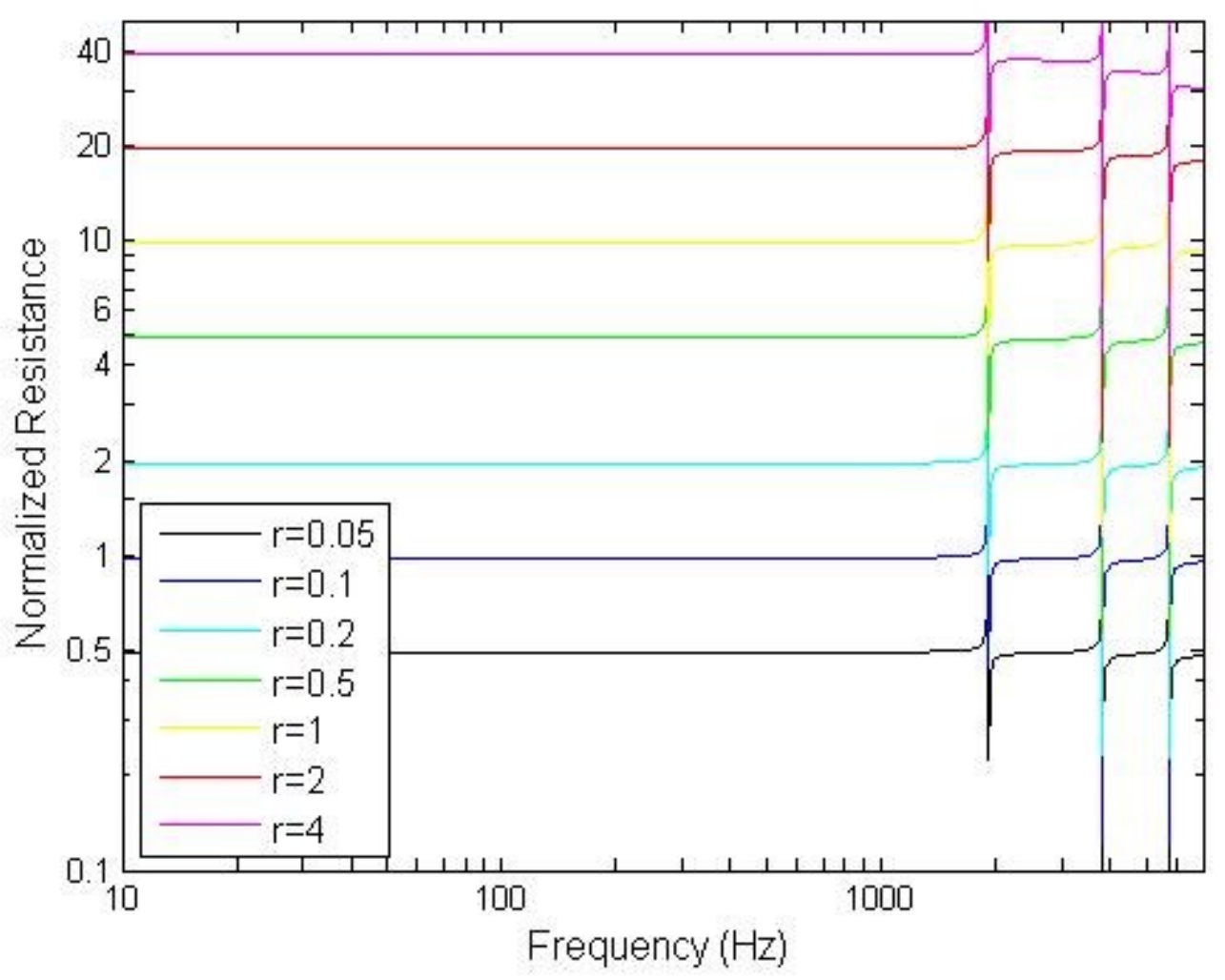

Fig. 8 